\title{
Pengaruh Dopan pada Sifat Optik Poli(heksil tiofen)
}

\author{
Fitrilawati, ${ }^{*}$ Wildan Abdussalam, Yusi S. Syamsiar, dan Tuti Susilawati \\ Laboratorium Fisika Material, \\ Jurusan Fisika FMIPA, Universitas Padjadjaran \\ Kampus Jatinangor, Sumedang 45363 \\ Rahmat Hidayat \\ Laboratorium Fisika Bahan Magnetik dan Fotonik, \\ Program Studi Fisika FMIPA, Institut Teknologi Bandung \\ Jl. Ganesha No.10, Bandung 40132
}

\begin{abstract}
Intisari
Poli(heksil tiofen) adalah polimer terkonjugasi yang memiliki gugus rantai samping heksil. Polimer tersebut memiliki keunikan yang khusus dibandingkan polimer terkonjugasi lainnya, khususnya pada sifat optik, sifat listrik dan stabilitas optiknya. Sifat optik dan sifat listrik perlu dipahami untuk mengetahui struktur elektronik bahan. Makalah ini membahas sifat optik, yaitu indeks bias dan koefisien absorbsi, poli(heksil tiofen) dengan yang didoping $\mathrm{FeCl}_{3}$ dengan variasi konsentrasi yang berbeda. Film tipis polimer dibuat dengan teknik solution casting dari poli(heksil tiofen) yang dilarutkan dalam toluen. Spektrum UV-Vis diukur diukur secara insitu yaitu saat doping film poli(heksil tiofen) dengan $\mathrm{FeCl}_{3}$ berlangsung. Indeks bias dan koefisien absorbsi dihitung dari data spektrum absorbsi dengan menggunakan perumusan Kramers Kronig. Hasil yang didapat menunjukkan adanya pengaruh dopan terhadap indeks bias dan koefisien absorbsi poli(heksil tiofen).
\end{abstract}

KATA KUNCI: polimer terkonjugasi, poli(heksil tiofen), doping, spektroskopi insitu

\section{PENDAHULUAN}

Penelitian polimer terkonjugasi banyak dilakukan oleh berbagai kelompok karena bahan ini memiliki sifat listrik dan optik yang menarik serta mempunyai banyak potensi aplikasi. Perkembangan tersebut diawali dengan penemuan poliasetilen yang memiliki konduktivitas setara dengan tembaga oleh kelompok Heeger, McDiarmid, dan Shirakawa [1]. Berkat penemuannya tersebut, ketiganya mendapat hadiah nobel Kimia pada tahun 2000 [2].

Dalam perkembangan selanjutnya, banyak jenis polimer terkonjugasi lain yang dibuat seperti poli(fenil vinilen) beserta turunannya, politiofen beserta turunannya, dan polipirol beserta turunannya [3]. Polimer tersebut memiliki berbagai aplikasi, seperti fotodioda dan organic field effect transistor. Berkaitan aplikasi tersebut banyak dikaji tentang efek dopan terhadap sifat konduksi bahan polimer terkonjugasi. Berbagai kelompok melakukan doping dengan dopan yang berbeda, Alan G. McDiarmid menggunakan dopan iodin $\left(\mathrm{I}_{2}\right)$ untuk mempelajari perubahan konduktivitas poliasetilen[2]. J.D. Hettinger menggunakan dopan $\mathrm{FeCl}_{3}$ untuk mempelajari mekanisme konduksi pada film tipis Langmuir-Blodget poli-(heksil tiofen)[4]. Ramadhar Singh menggunakan dopan $\mathrm{FeCl}_{3}$ untuk mempelajari mekanisme konduksi pada poli(metiltiofen)[5].

Politiofen adalah salah satu jenis polimer terkonjugasi yang disintesis dari monomer tiofen. Poli-(heksil tiofen) merupakan salah satu turunan politiofen yang memiliki modifikasi

*E-MAIL: fitrilawati@unpad.ac.id (a)

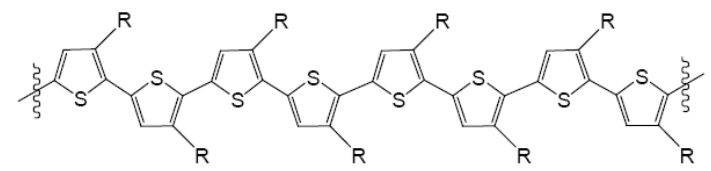

(b)

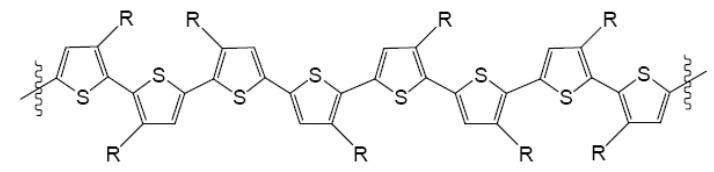

Gambar 1: Struktur poli(heksil tiofen) (a) regioregular, (b) regiorandom

gugus samping heksil. Polimer ini dapat memiliki dua konfigurasi yaitu regioregular dan regiorandom, yang strukturnya diperlihatkan pada Gambar 1 [7]. Poli-(heksil tiofen) regioregular memiliki pasangan gugus samping yang beraturan. Struktur gugus samping yang beraturan mengakibatkan kemudahan proses konduksi sehingga lebih konduktif. Polimer ini diaplikasikan dalam pembuatan O-FET, O-LED (light emitting diode), dan PEDOT (piezo electric) [7].

Poli-(heksil tiofen) regiorandom memiliki pasangan gugus samping yang acak (random). Struktur gugus sampingnya yang acak membuatnya kehilangan ikatan konjugasi. Polimer ini banyak diaplikasikan dalam pembuatan fotodioda [8]. Pada tulisan ini akan dikaji salah satu turunan dari politiofen, yaitu pengaruh dopan terhadap sifat optik poli-(heksil tiofen). 


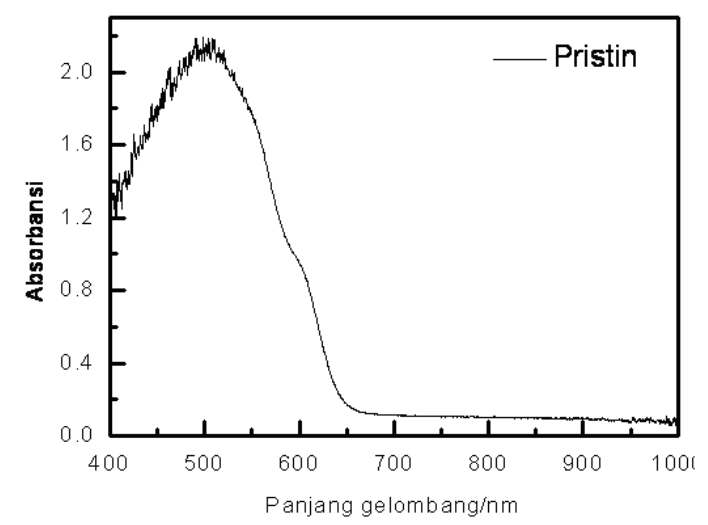

Gambar 2: Spektrum UV-Vis poli-(heksil tiofen) pristin di dalam akuades.

\section{EKSPERIMEN}

Dalam eksperimen yang dilakukan terdapat beberapa tahap, yaitu penyiapan film tipis polimer, doping dan pengukuran spektrum UV-Vis. Dalam pembuatan film tipis, pertama dilakukan penyiapan larutan poli-(heksil tiofen). Dalam pembuatan larutan polimer dipergunakan pelarut toluene. Larutan dengan konsentrasi $0,5 \%$ disiapkan dengan mencampurkan 0.0435 gr poli-(heksil tiofen) dan $10 \mathrm{ml}$ pelarut toluene. Tahap selanjutnya adalah penyiapan substrat. Substrat yang dipergunakan adalah kaca mikroskop yang berukuran $(2,5 \mathrm{~cm}$ $1,25 \mathrm{~cm})$. Substrat kaca tersebut dicuci dengan teepol untuk menghilangkan lapisan lemak dan kotoran yang lain. Kemudian, substrat tersebut secara berturut-turut dibilas dengan akuades dan aseton panas lalu dikeringkan. Film tipis disiapkan dengan teknik solution casting. Film yang terbentuk selanjutnya dikenakan proses annealing di dalam oven dengan suhu $50^{\circ} \mathrm{C}$ selama 2 jam.

Dopan yang digunakan adalah $\mathrm{FeCl}_{3}$ dengan konsentrasi $0,1 \mathrm{M}$ dan 0,5M, Doping dilakukan dengan mencelupkan film poli(heksil tiofen) ke dalam larutan dopan selama waktu tertentu. Pengukuran spektrum UV-Vis sampel yang didoping dilakukan secara insitu, yaitu pengukuran spektrum sampel saat proses doping berlangsung. Alat ukur yang digunakan adalah USB 2000 Ocean Optic. Peralatan tersebut terdiri dari sel tempat sampel, detektor dan sumber cahaya tungsten. Alat ini mempunyai jangkauan panjang gelombang 300nm sampai dengan $1100 \mathrm{~nm}$.

\section{HASIL DAN PEMBAHASAN}

Spektrum film poli(heksil tiofen) yang tidak mengandung dopan (pristin) yaitu di dalam sel berisi akudes sebelum didoping dengan $\mathrm{FeCl}_{3}$ diperlihatkan pada Gambar 2. Spektrum tersebut memiliki puncak absorbsi $\left(\lambda_{m a k s}\right)$ pada panjang gelombang sekitar $504 \mathrm{~nm}$ dan shoulder pada panjang gelombang $600 \mathrm{~nm}$. Data tersebut menunjukan poli-(heksil tiofen) memiliki band gap sekitar 1,9 eV. Angka ini setara dengan bahan semikonduktor.
Sifat optik yang berupa indeks bias dan koefisien absorsi ditentukan dari suseptibilitas listrik bahan yang dinyatakan dengan komponen real dan imajiner. Nilai real dari suseptibilitas adalah indeks bias bahan dan imajiner adalah koefisien absorpsi bahan. Dalam pengukuran spektroskopi, nilai n (indeks bias) dan $\alpha$ (koefisien absorpsi) didefinisikan sebagai

$$
\begin{aligned}
n & =\sqrt{1+\operatorname{Re}\left(\chi^{(-1)}\right)} \\
\alpha & =\frac{k_{\circ}}{n} \operatorname{Im}\left(\chi^{(-1)}\right)
\end{aligned}
$$

dengan $\chi^{(1)}$ adalah suseptibilitas linier dan $\mathrm{k}_{\circ}$ adalah konstanta propagasi. Modus pengukuran spektrum yang dipergunakan berupa absorpsi sehingga datanya berupa absorbansi (A) atau optical density (OD) yang didefiniskan sebagai log $\left(\mathrm{I}_{\circ} / \mathrm{I}\right)$. Konstanta optik linier $\alpha$ ditentukan dari hasil pengukuran tersebut dengan menggunakan persamaan Lambert-Beer $\left(\mathrm{I}=\mathrm{I}_{\circ} \mathrm{e}^{-\alpha d}\right)$ dan data ketebalan film seperti pada Pers.(3).

$$
\alpha=2,3 \frac{O D}{d}
$$

Selanjutnya, konstanta optik linier n dihitung dari data spektrum absorbansi dengan menggunakan perumusan KramersKronig (KK). Untuk mengevaluasi n, permitivitas listrik bahan dinyatakan dalam bentuk kompleks, $\epsilon=\epsilon_{1}+i \epsilon_{2}$, dengan $\epsilon_{1}$ dan $\epsilon_{2}$ masing-masing adalah bagian real dan imajiner.

$$
\epsilon_{1}(\omega)=\epsilon_{b}+\frac{2}{\pi} \int \frac{\omega^{\prime} \epsilon_{2}\left(\omega^{\prime}\right)}{\omega^{\prime 2}-\omega^{2}} d \omega^{\prime}
$$

Andaikan indeks bias kompleks dari bahan diungkapkan oleh $(\mathrm{n}+\mathrm{i} \kappa)$, maka berdasarkan hubungan $\sqrt{\epsilon_{1}+i \epsilon_{2}}=(\mathrm{n}+\mathrm{i} \kappa)$ dapat dituliskan

$$
\begin{aligned}
& \epsilon_{1}(\omega)=n^{2}(\omega)-\kappa^{2}(\omega) \\
& \epsilon_{2}(\omega)=2 n(\omega) \kappa(\omega)
\end{aligned}
$$

suku $\epsilon_{b}$ dalam Pers.(4) adalah suku koreksi permitivitas (background permitivity) yang memasukan efek absorpsi UV pada daerah luar jangkauan spektrometer. Besaran $\mathrm{n}(\omega)$ dan $\kappa(\omega)$ pada Pers.(5) dan Pers.(6), masing-masing adalah bagian real dan imajiner indeks bias. Bagian imajiner $\kappa(\omega)$ dapat dihitung dengan menggunakan data absorbansi seperti yang ditunjukan oleh Per.(7).

$$
\kappa(\omega)=\frac{\lambda \alpha}{4 \pi}
$$

Dengan menggunakan persamaan di atas, Pers.integral (4) dapat diseleseikan dengan iterasi numerik. Dalam perhitungan tersebut, dilakukan aproksimasi pada iterasi pertama dengan menganggap indeks bias pada seluruh spektrum adalah konstan, $\mathrm{n}(\omega)=\mathrm{n}_{\circ}$.

Dalam makalah ini, indeks bias dan koefisien absorsi dihitung dengan metode Kramers-Kronig menggunakan program KKNEW yang dikembangkan di Max Planck Institute for Polymer Research, Mainz, Jerman. Ketebalan film sekitar $1 \mu \mathrm{m}$ dan input data yang dipakai adalah spektrum absorbansi dengan jangkauan panjang gelombang $400 \mathrm{~nm}$ sampai dengan $1000 \mathrm{~nm}$. Perhitungan dilakukan secara iterasi 


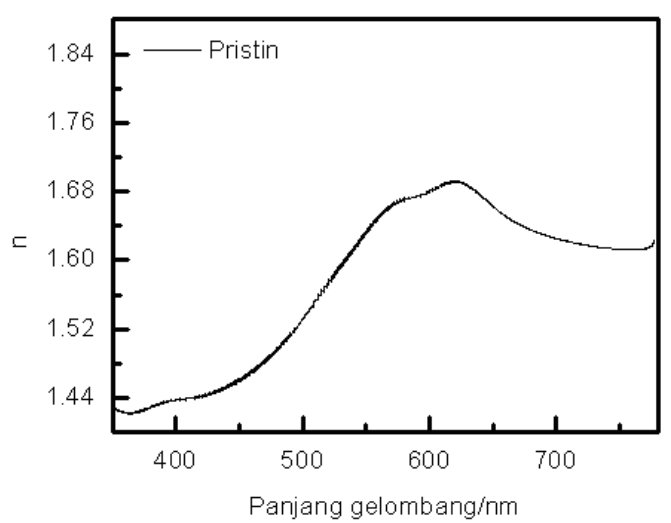

Gambar 3: Kurva dispersi indeks bias poli-(heksil tiofen) pristin yang dihitung dengan program KKNEW

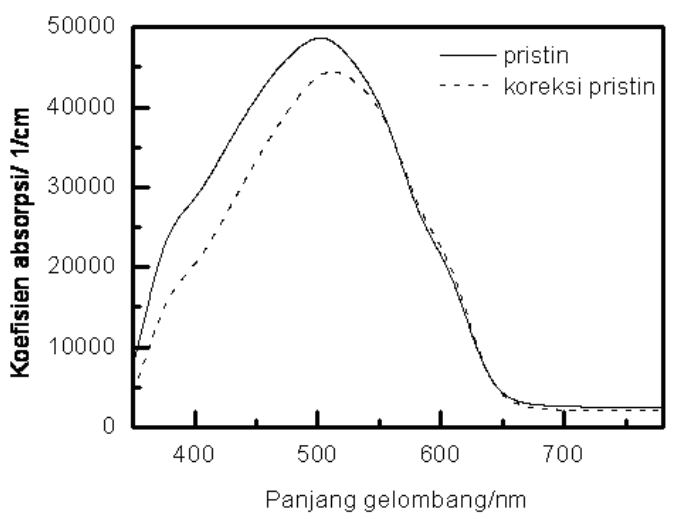

Gambar 4: Perbandingan koefisien absorpsi antara poli-(heksil tiofen) pristin dengan hasil koreksi program KKNEW

dengan data awal indeks bias $\left(\mathrm{n}_{\circ}\right)$ 1,5 dan konstanta dielektrik 2,3 . iterasi dilakukan sehingga mencapai nilai delta $(\Delta)$ sekitar $10^{-4}$. Hasil perhitungan berupa data file yang masingmasing berupa n sebagai fungsi $\lambda$ dan optical density yang sudah dikoreksi terhadap refleksi sebagai fungsi panjang gelombang.

Untuk perhitungan indeks bias dan koefisien absorpsi dilakukan proses smoothing data dengan menggunakan software Microcal origin. Data absorbansi yang dimasukan dalam perhitungan tersebut jangkauan dari $350 \mathrm{~nm}$ sampai $1000 \mathrm{~nm}$. untuk data indeks bias, data yang di-inputkan dari $350 \mathrm{~nm}$ sampai $780 \mathrm{~nm}$. Kurva dispersi indeks bias poli(heksil tiofen) pristin hasil perhitungan diperlihatkan pada Gambar 3. Dari gambar dispersi tersebut tampak bahwa besar indeks bias poli(heksil tiofen) pada $633 \mathrm{~nm}$ sekitar 1,65.

Untuk data koefisien absorpsi, data yang di-inputkan dari $350 \mathrm{~nm}$ sampai $780 \mathrm{~nm}$. Kurva koefisien absorpsi hasil perhitungan diperlihatkan pada Gambar 4. Dari gambar tersebut tampak bahwa film pristin memiliki koefisien absorpsi sekitar $48661 \mathrm{~cm}^{-1}$ pada $\lambda_{\max } 502 \mathrm{~nm}$. Setelah dikoreksi, terjadi pergeseran $\lambda_{\max }$ menjadi $513 \mathrm{~nm}$ dan penurunan koefisien absorpsi sekitar $8,7 \%$.

Selanjutnya, hasil pengukuran spektrum UV-Vis film poli-

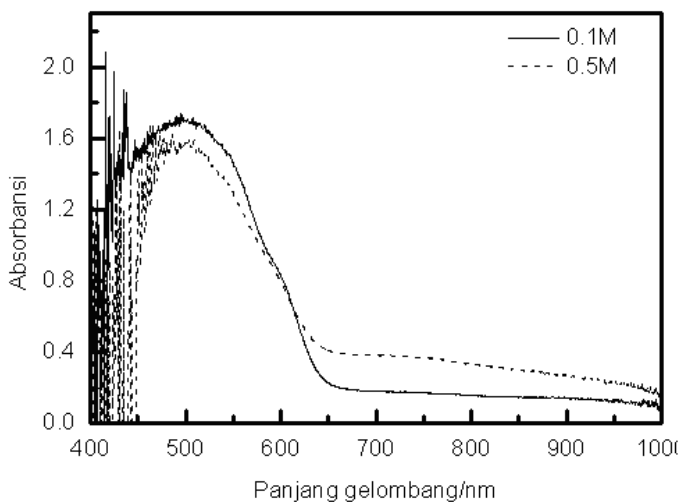

Gambar 5: Perbandingan spektrum poli-(heksil tiofen) yang didoping dengan $0.1 \mathrm{M} \mathrm{FeCl}_{3}(-)$, film yang didoping dengan $0.5 \mathrm{M} \mathrm{FeCl}_{3}$ (一).

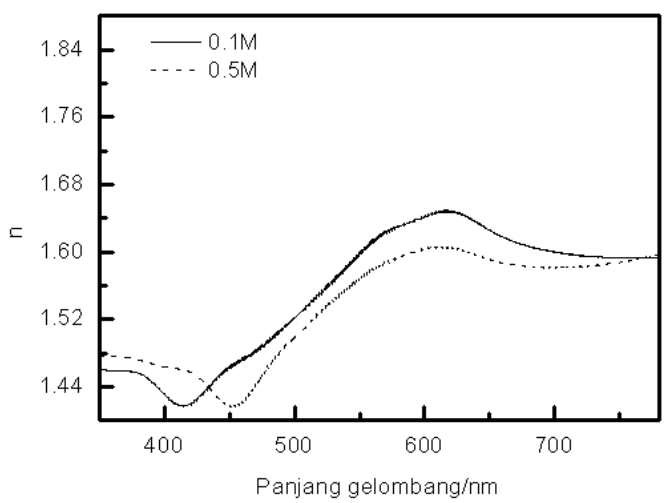

Gambar 6: Perbandingan kurva dispersi indeks bias poli(heksil tiofen) yang didoping dengan $0.1 \mathrm{M} \mathrm{FeCl}_{3}(-)$,dan yang didoping dengan $0.5 \mathrm{M} \mathrm{FeCl}_{3}(-)$.

(heksil tiofen) yang didoping pada berbagai level dopan $\mathrm{FeCl}_{3}$ diperlihatkan pada Gambar 5. Tampak bahwa doping dengan $0,1 \mathrm{M} \mathrm{FeCl}{ }_{3}$ selama 90 menit menghasilkan pergeseran $\lambda_{\max }$ ke arah panjang gelombang pendek (blue shift). Jika sebelum didoping $\lambda_{\max } 502 \mathrm{~nm}$, maka setelah didoping menjadi $493 \mathrm{~nm}$. Selain itu terjadi penurunan absorbansi sekitar $3,5 \%$. Namun, bersamaan dengan penurunan absorbansi pada $\lambda_{\max } 493 \mathrm{~nm}$ terjadi pula peningkatan absorbansi pada selang panjang gelombang $650 \mathrm{~nm}$ sampai $1000 \mathrm{~nm}$ sekitar 5,9\%.

Tampak pula bahwa ketika konsentrasi dopan $\mathrm{FeCl}_{3}$ ditambah menjadi $0.5 \mathrm{M}, \lambda_{\max }$ berubah menjadi $486 \mathrm{~nm}$ dan absorbansi turun pada $\lambda_{\max } 486$ sekitar $11,7 \%$. Sama seperti ketika didoping dengan $0.1 \mathrm{M} \mathrm{FeCl}$, terjadi pula peningkatan absorbansi pada selang panjang gelombang $650 \mathrm{~nm}$ sampai $1000 \mathrm{~nm}$ sekitar $18.2 \%$.

Selanjutnya, hasil perhitungan indeks bias film poli-(heksil tiofen) yang didoping pada berbagai level dopan $\mathrm{FeCl}_{3}$ diperlihatkan pada Gambar 6. Tampak bahwa doping 0,1M dan $0,5 \mathrm{M} \mathrm{FeCl}_{3}$ menghasilkan penurunan indeks bias pada panjang gelombang $663 \mathrm{~nm}$. Jika sebelum didoping $\lambda_{\text {merah }} 663$ $\mathrm{nm}$, maka setelah didoping $0,1 \mathrm{M}$ dan $0,5 \mathrm{M} \mathrm{FeCl}$ terjadi penurunan indeks bias sekitar $14.2 \%$ untuk $0,1 \mathrm{M} \mathrm{FeCl}_{3}$ dan 


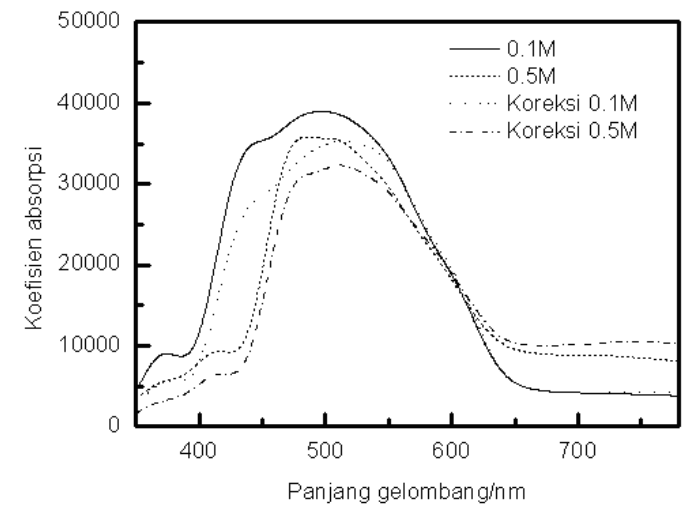

Gambar 7: Grafik perbandingan koefisien absorpsi poli-(heksil tiofen) pada berbagai level dopan $\mathrm{FeCl}_{3}$, film yang didoping dengan $0.1 \mathrm{M} \mathrm{FeCl}_{3}$ (-), film yang didoping dengan $0.5 \mathrm{M} \mathrm{FeCl}_{3}$ (-), hasil koreksi KKNEW $0.1 \mathrm{M} \mathrm{FeCl}_{3}$ (......), dan hasil koreksi KKNEW $0.5 \mathrm{M} \mathrm{FeCl}_{3}(-.-\ldots-)$.

$25 \%$ untuk $0.5 \mathrm{M} \mathrm{FeCl}_{3}$. Dari hasil di atas tampak bahwa penambahan konsentrasi dopan $\mathrm{FeCl}_{3}$ menghasilkan penurunan indeks bias poli-(heksil tiofen) yang jelas.

Selanjutnya, hasil pengukuran koefisien absorpsi film poli(heksil tiofen) yang didoping pada berbagai level dopan $\mathrm{FeCl}_{3}$ diperlihatkan pada Gambar 7. Dari gambar tersebut tampak bahwa doping $0,1 \mathrm{M} \mathrm{FeCl} 3$ selama 90 menit menghasilkan pergeseran $\lambda_{\max }$ ke arah panjang gelombang pendek (blue shift). Jika sebelum didoping $\lambda_{\max } 502 \mathrm{~nm}$, maka setelah didoping menjadi $499 \mathrm{~nm}$. Selain itu terjadi penurunan koefisien absorpsi sekitar 20\%. Bersamaan dengan penurunan koefisien absorpsi pada $\lambda_{\max } 499 \mathrm{~nm}$ terjadi peningkatan koefisien absorpsi pada selang panjang gelombang $650 \mathrm{~nm}$ sampai $1000 \mathrm{~nm}$ sekitar $7 \%$. Ketika konsentrasi dopan $\mathrm{FeCl}_{3}$ ditambah menjadi $0,5 \mathrm{M}, \lambda_{\max }$ berubah menjadi $483 \mathrm{~nm}$ dan koefisien absorpsi turun pada $\lambda_{\max } 483$ sekitar 26,4\%. Sama seperti ketika didoping dengan $0,1 \mathrm{M} \mathrm{FeCl}_{3}$, terjadi pula peningkatan koefisien absorpsi pada selang panjang gelombang $650 \mathrm{~nm}$ sampai $1000 \mathrm{~nm}$ sekitar 16,6\%.

Dari hasil di atas tampak bahwa penambahan konsentrasi dopan $\mathrm{FeCl}_{3}$ menghasilkan blue shift yang jelas dan penurunan koefisien absorpsi pada $\lambda_{\max }$ yang besar serta peningkatan koefisien absorpsi pada selang panjang gelombang $650 \mathrm{~nm}$ sampai $1000 \mathrm{~nm}$ yang besar.

\section{SIMPULAN}

Hasil eksperimen yang dilakukan telah berhasil membuktikan pengaruh konsentrasi dopan $\mathrm{FeCl}_{3}$ terhadap sifat optik poli-(heksil tiofen). Penambahan konsentrasi dopan $\mathrm{FeCl}_{3}$ menghasilkan blue shift, penurunan absorbansi, indeks bias, dan koefisien absorpsi. Selain itu, penambahan konsentrasi dopan $\mathrm{FeCl}_{3}$ menghasilkan kenaikan absorbansi dan kenaikan koefisien absorpsi pada selang panjang gelombang $650 \mathrm{~nm}$ sampai $1000 \mathrm{~nm}$.

\section{Ucapan Terima Kasih}

Penelitian ini dibiayai oleh Research Grant Proyek TPSDP Tahun Anggaran 2006 berdasarkan surat perjanjian No. 055/SPMU-UNPAD/RG/2006.
[1] Ulf Sandstrm, Agneta Tissel, Electrically Conducting Polymers in Sweden, report Sweden, 2000.

[2] Alan G. McDiarmid, Syntheyic Metals : A Novel Role for Organic Polymers (Angew Chem. Int. Ed. 40, 2581-2590. USA, 2001).

[3] R.E.Siregar, Yayah Yuliah, Vany N. Sari, R. Hardisanto, Fotovoltaik Polimer PPV, KFI Vol. 10, No.2, Fisika UNPAD, 1999.

[4] E. Punkka, M.F. Rubner, J.D. Hettinger, J.S. Brooks, S.T. Hannahs, The American Physical Society. Vol 43, No.11, USA (1991).

[5] R. Singh, A. Kaur, Kanhaiya, D. Bhattacharya, Mechanism of DC Conduction in Ferric Chloride Doped Poly(3-methyl thiophene), Elsevier Science Vol 1567-1739, No.2 (2002).

[6] www. polythiophene - wikipedia. org, The free encyclopedia, 30 Januari 2007.

[7] Zein, Ahmad, Charge Transport in poly(3-hexylthiophene) and in Highly Soluble Oligothiophene Field-Effect Transistor, $\mathrm{PhD}$ thesis, Berlin, University of Postdam, 2006.

[8] Manueli, Alessandro, Influences of Printing Techniques on the Electrical Performances of Conjugated Polymers for Organic Transistors, dissertation Dr.-Ing., Chemnitz University, 2006.

[9] R. D. McCullough, R. D. Lowe, M. Jayaraman, D. L. Anderson, J. Org. Chem., 58, 904 (1993).

[10] C. K. Chiang, C. R. Fincher, Jr., Y. W. Park, A. J. Heeger, H.Shirakawa, E. J. Louis, A. G. MacDiarmid, Phys. Rev. Lett., 39, 1098 (1977); C. K. Chiang, M. A. Druy, S. C. Gau, A. J. Heeger, E. J. Louis, A. G. MacDiarmid, J. Am. Chem. Soc., 100, 1013 (1978).

[11] J. Heeger, Handbook of Conducting Polymers, E. R. L. Skotheim T. A., Reynolds J. R., Ed. (Marcel Dekker, Inc., New York, ed. 1st.1986). 